Research Square

\title{
How would COVID-19 protocols have impacted on continuity of care of hypertension patients
}

\author{
Seo Yoon Lee \\ University of Illinois at Chicago \\ Sung Youn Chun \\ National Health Insurance Service Ilsan Hospital \\ Hyeki Park ( $\square$ hyekipark@gmail.com ) \\ Health Insurance Review and Assessment Service
}

\section{Research Article}

Keywords: Continuity of care, Most Frequent Provider Continuity, Social distancing, Social isolating, Primary care, Telemedicine

Posted Date: August 26th, 2021

DOI: https://doi.org/10.21203/rs.3.rs-799317/v1

License: (a) This work is licensed under a Creative Commons Attribution 4.0 International License. Read Full License 


\section{Abstract}

Objective

To investigate the impact of the coronavirus disease 2019 (COVID-19) pandemic on the continuity of care (COC) in hypertension patients. Additionally, the factor of whether participants were treated by telemedicine or not was also considered.

Methods

National Health Insurance and Medical Aid claims This study used data from the Republic of Korea between 2019 and 2020 . The multiple regression analysis was performed to identify the differences in visits and the Most Frequent Provider Continuity (MFPC) of hypertensive patients before and after the COVID-19. To confirm the effect of telemedicine, additional analysis was performed with data that deleted cases that received telemedicine.

Findings

A total of 5,791,812 hypertensive patients are included in this study. When the confounding variables were adjusted, the MFPC decreased by 0.0031 points after the COVID-19. It also showed the same results for MFPC when telemedicine cases were excluded. The number of outpatient clinic visit days decreased by 0.2930 days after the COVID-19. Without telemedicine cases, the number of outpatient clinic visit days decreased by 0.3330 days after the COVID-19.

Conclusion

The COVID-19 protocols did not affect hypertension patients' COC but impacted their outpatient frequency. Additionally, when telemedicine cases are considered, COC was the same, but the patient's outpatient frequency had decreased, but not as much as when telemedicine cases were considered.

\section{Introduction}

Hypertension is a chronic disease that requires healthcare provider routine management. The hypertension prevalence rate has increased due to the aging population, westernized eating habits, and high sodium consumption. Among the population aged over 20 , the estimated hypertension prevalence is $29 \%$, and among the patients diagnosed with hypertension, the controlling rate is only $47 \%{ }^{1}$. High blood pressure is the most important modifiable risk factor with the most significant influence on cardiovascular or cerebrovascular diseases ${ }^{2,3}$. According to the National Health Insurance Service (NHIS) statistics in Korea, the estimated medical cost of treating hypertension was 3.83 trillion Korean Won (i.e., 3.4 billion U.S. dollars). This amount is equivalent to $4 \%$ of all medical expenses and $16 \%$ of medical expenses for chronic diseases ${ }^{1,3}$. Thus, controlling the hypertension prevalence by continuous monitoring and management would reduce the tremendous financial burden caused by the disease and eventually improve the patient's quality of life.

According to Shortell ${ }^{4}$, the continuity of care (COC) is defined as "the extent to which services are received as part of a coordinated and uninterrupted succession of events consistent with the medical care needs of patients." It is well-recognized that patients receiving continuous care from regular healthcare providers have better health outcomes and higher patient satisfaction at a lower cost ${ }^{5}$. Among hypertension patients, the greater COC, the lesser risk of hospital admission was reported ${ }^{6}$. Additionally, $\mathrm{COC}$ is also associated with a decreased use of emergency room visits and better followup rates with appointments 7,8 . This could be due to the fact that the rapport built with the patient allows the healthcare providers to have a better knowledge about the patient and instantly recognize the changes in their health status. This can eventually prevent the patients from suffering from complications or disease onsets. Thus, in order to control high blood pressure, $\mathrm{COC}$ is an important concept.

On March 11th, 2020, the World Health Organization declared coronavirus disease 2019 (COVID-19) a pandemic. A response to the pandemic declaration, social distancing and isolation were recommended and done to prevent the virus from spreading. Many researchers showed concerns of a negative impact of social isolation on outpatient and primary care ${ }^{9,10}$. However, telemedicine was also enlighten as an effective method to treat patients in such situation ${ }^{11}$. Korean government also temporarily approved to provide medical counseling and prescription in non-face-to-face method which is over the telephone call. Considering the fact that the unprecedented length of the social isolation period would significantly impact the patients' outcomes who require continuous care by healthcare providers; the study might be the first to provide information about the influence of a pandemic on $\mathrm{COC}$ of hypertension patients and how the telemedicine will reduce its impact in South Korea. Thus, this article aims to investigate the impact of the COVID-19 pandemic protocol on the COC to hypertension patients. Additionally, whether patients received telemedicine or not is considered.

\section{Methods}

\section{Source of data}

This study analyzed the medical use of patients with hypertension by using the outpatient statements of the National Health Insurance (NHI) and Medical Aid beneficiaries that were claimed by the Korea Health Insurance Review and Assessment Service (HIRA). Over 95\% of all Koreans are compulsorily insured by $\mathrm{NHI}$ and Medical Aid. In order to evaluate the impact of the COVID-19 outbreak, the cases treated between January 20 , at the 
beginning of COVID-19 in Korea, and December 31, 2020 were considered in the study. For comparison, the cases between January 20 and December 31 , 2019 were considered. In order to compare COC under the same conditions, the data was limited to cases reviewed by the March of the following year.

Among those receiving hospitalization or outpatient treatment for hypertension $(110,111,112,113)$ as their major diagnosis or sub-diagnosis, patients who have been prescribed antihypertensive drugs twice or more on different days, and the total number of administration days is 7 days or more, between January and December 2019 were defined as hypertensive patients. Of these, the total number of the study population was 5,791,812, excluding the fatalities before December 31,2020 , and those who did not meet the study conditions. This study was exempt from institutional review board of HIRA review due to the data being used were deidentified which are available for public use by the HIRA.

\section{Variables}

\section{Dependent variables}

\section{Number of visits}

The frequency of visits to a medical institution is a representative variable that can measure the volume of medical use. It is suitable for measuring medical usage changes due to COVID-19 protocols due to its consistency compared to the expenses affected by the medical practices. In this study, the number of outpatient-visits due to hypertension as the major diagnosis or sub-diagnosis during each study period was defined as the number of visits.

\section{Most Frequent Provider Continuity (MFPC)}

In chronic disease management, the relationship continuity between doctor and patient, a type of the COC, is known to have a positive effect on the treatment process, outcome, and cost. MFPC is a representative tool that can measure COC when the measurement target is an individual patient in a situation where the attending physician is not determined. In this study, MFPC was calculated by counting the total number of visits to medical institutions due to hypertension as the denominator and the number of visits to the most visited institution as the numerator during each study period. It has a value between 0 and 1, and the closer it is to 1, the higher the MFPC. If the frequency of the visits is too low, there is a possibility that the MFPC will be measured too high. Therefore, those who visited medical institutions less than twice per year were excluded.

\section{Variable of interests}

In order to evaluate the impact of the COVID-19 outbreak on the patients' medical use behavior, the period between January 20, when the first COVID-19 case was confirmed in Korea, and December 31, 2020 was defined as the period after importation (After). The same period in the previous year, with no COVID-19, was defined as the period before importation (Before).

\section{Confounding variables}

The variables with an impact on medical use, such as the patient's gender, age, region of residence, insurance type, Charlson Comorbidity Index (CCI), diabetes status, duration of hypertension and type of medical institution most frequently used, were adjusted. Any change in the region of residence or insurance type during the study period, led to the exclusion of the patients from the study.

$\mathrm{CCl}$ is a representative tool that can measure the severity of patients' underlying condition in administrative data such as health insurance claim data that lacks clinical information. Nineteen of the comorbidities included in the $\mathrm{CCl}$ calculation were included in the hospitalization and outpatient statements for a year before each study period as major diagnoses or sub-diagnosis (weights of 1 to 6 points were given to each morbidity and calculated). The bigger score implies the more serious underlying condition. Diabetes mellitus was initially included in CCI but was excluded because it was measured separately in this study. Diabetes mellitus was defined if E10 to E14 were claimed as major diagnoses or sub-diagnosis in hospitalization and outpatient statements for 1 year prior to the study period.

\section{Statistical analyses}

In this study, Chi-square test and independent t-test were performed to identify the general characteristics of the study populations. The multiple regression analysis and independent t-test were performed to identify the differences in the number of visits to medical institutions and the MFPC of hypertensive patients before and after the COVID-19 importation. In the multiple regression analysis, the patient's gender, age, region of residence, insurance type, $\mathrm{CCl}$, diabetes status, duration of hypertension and type of medical institution most frequently used were adjusted. To consider the repeated measurement, a generalized estimating equation model was used, and CORRW type was applied for the covariance structure. In addition, to confirm the effect of telemedicine (non-face-to-face telephone consultation and prescription, untact treatment is used by Korean government), temporarily permitted because of the COVID-19 pandemic since February 24, 2020, additional analysis was performed with data that deleted telemedicine cases. SAS Enterprise Guide 7.1 was used for all statistical analysis.

\section{Results}

\section{Characteristics of the study population}

Table 1 shows the general characteristics of the study populations. A total of 5,791,812 hypertensive patients, 2,826,779 males and 2,965,033 females are included. During the Before period, 2,446,950 (42.25\%) of the population accounted for the 60-74-year-olds at the highest proportion. Among the 
study case population, $1,394,230$ patients (24.07\%) had diabetes, and those with more than 10 years of hypertension (2,978,121 or $51.42 \%)$ were among the majority with the mean $\mathrm{CCl}$ of 0.6347 . As for the type of insurance, $\mathrm{NHI}$ accounted for the majority with 5,526,514 (95.42\%). By region, Gyeonggi Province had the largest number of residents at 1,366,235 (23.59\%), followed by Seoul at 985,945 (17.02\%) and Busan at 407,245 (7.03\%). The most frequently used medical institutions before the appearance of COVID-19 were clinics $(4,537,548,78.34 \%)$, and the proportion increased to $4,677,502$ $(80.76 \%)$ after the appearance of COVID-19. After the manifestation of the virus the proportion of tertiary hospitals and general hospitals increased by $0.01 \% \mathrm{p}$ and $0.03 \% \mathrm{p}$, respectively, and the proportions of hospitals and public health institutions decreased by $0.09 \% \mathrm{p}$ and $2.37 \% \mathrm{p}$, respectively.

Table 2 shows the MFPC before and after the importation of COVID-19. The MFPC in the Before period was 0.9507, and after the appearance of the virus, it decreased by 0.0024 to 0.9483 , which was statistically significant. By patient characteristics, MFPC significantly decreased after the importation of COVID-19 in most groups, but there were some groups that increased. By age, MFPC decreased in all groups over 60 years old (60 to $74:-0.0033 ; 75$ and more: -0.0057 ), and it increased in all groups under 60 years old ( 0 to $20:+0.0066 ; 30$ to $44:+0.0047 ; 45$ to 69 : +0.0008 ), and it was statistically significant. Based on the hypertension duration, the MFPC increased from 0.9373 points to 0.9467 points after the COVID 19 appearance in groups with less than 2 years of hypertension and it decreased significantly in groups with a longer period of hypertension. By region MFPC increased in Jeju Island by 0.0039 points, Gyeongsangnam-do 0.0024 points, Jeollabuk-do 0.0031 points, Daegu 0.0014 points increased, and it decreased significantly in other areas, with no statistically significant difference in Sejong, Chungcheongnam-do, Daejeon and Incheon. By the most frequently used medical institutions, the MFPC increased in tertiary general hospitals (0.0033 points), general hospitals (0.0009 points), and hospitals (0.0047 points), while it decreased in clinics (-0.0024 points) and public health institutions (-0.0507 points).

Table 3 shows the number of visits per patient before and after the appearance of COVID-19. The number of visit days before COVID-19 was 8.3347 days, which decreased significantly statistically to 8.1363 days thereafter. By patient characteristics, the number of visits significantly decreased in all population groups except for the population with a prevalence of hypertension in the past 2 years. In particular, there was a greater decrease in the number of visits among women (before: 8.6337, after: 8.4084), patients of 75 and over (before: 9.3258, after: 8.9850), patients with diabetes (before: 9.0337, after: 8.7701), patients with over 10 years of hypertension (before: 8.6758, after: 8.4107), medical aid beneficiaries (before: 10.3710, after: 10.1173), residents of Sejong-si (before: 8.5040, after: 8.2302), and those who mainly use public health institutions (before: 6.0694, after: 5.6009 ).

\section{Multiple linear regression analysis}

Table 4 shows the results of the multiple regression analysis for MFPC. When the confounding variables were adjusted, the MFPC decreased by 0.0031 points after the appearance of COVID-19, which was statistically significant ( $p$-value <.0001). It also shows the results of the multiple regression analysis for MFPC when telemedicine case is excluded. When the independent variables were adjusted, the MFPC after the appearance of COVID-19 was significantly statistically decreased, which was the same as when telemedicine case was included ( $\beta$ : $-0.0031, p$-value $<.0001)$.

Table 5 shows the results of the multiple regression analysis on the number of visits per patient. When the confounding variables were adjusted, the number of visit days decreased by 0.2930 days after the appearance of COVID-19, which was statistically significant ( $p$-value <.0001). The result of multiple regression analysis on the number of visits per patient when telemedicine case is excluded is also shown. Upon the adjustment of the independent variables, the number of visits per patient after the appearance of COVID-19 decreased by 0.3330 days statistically, which is 0.04 days lower compared to when telemedicine case was included.

\section{Discussion}

The purpose of the study was to identify the impact of social distancing and isolating due to the COVID-19 pandemic on the COC and outpatient visit of hypertension patients. Considering the fact that there are no family doctors in the Korean healthcare system, this study used MFPC as a proxy of COC. To examine the impact, a multiple regression conducted comparing MFPC with outpatient visits during the pre to post pandemic period. The study found a significant decrease in the MFPC and outpatient visits during the pandemic. Although both MFPC and the number of outpatient visits decreased with statistical significance, they varied in volume.

This study found a decrease in the MFPC of hypertensive patients; the size of the beta coefficient was not big enough to be considered as a significant decrease. Additionally, regardless of the patients receiving telephone prescriptions, their MFPC reported the same. MFPC represents the pattern of outpatient usage ${ }^{12}$; thus, study results showed that even though the pandemic impacted and limited their access to outpatient visits, the pattern of outpatient usage remained the same. Since MFPC represents the pattern of medical care utilization, its results indicate that the medical care utilization patterns of hypertension patients have not been impacted despite the nationwide initiation of COVID-19 protocols. The majority of the previous studies reported the positive impact of $\mathrm{COC}$ on a patient's health behaviors and health outcomes; however, a few studies reported different results. COC is, specifically, associated with positive patient and provider satisfaction ${ }^{13}$, reduced emergency room use ${ }^{8}$, decreased hospital admissions, and better immunization rates ${ }^{14}$; on the contrary, $\mathrm{COC}$ by provider is not associated with blood pressure control ${ }^{7}$. However, there is a study showing that patients with high COC levels (0.67-1.0) were more likely to have better controlled blood pressure compared to those with medium (0.40-0.66) or low COC levels $(0-0.39)^{7}$. Better controlled blood pressure in hypertension patients leads to better health outcomes. Considering the results of these previous studies with the average MFPC of about 0.95, even with the COVID-19 protocols in effect, the health outcomes of the hypertension patient in Korea remained almost the same. 
The other result shown in the study is that the number of outpatient visits has decreased. Unlike the MFPC results, on the other hand, the size of the outpatient visit number decreased significantly after the COVID-19 pandemic. When considering the telemedicine case, the number of outpatient clinic visits decreased, but not as much as the patients who did not undergo the telemedicine. The number of outpatient clinic visits reflects the volume of medical use and measures the utilization of healthcare services ${ }^{15,16}$. Due to the COVID-19 protocols, unlike the medical care usage pattern, the utilization decrease was inevitable. However, as a result of telemedicine the frequency of outpatient visits has not gone down by much. Studies regarding the frequency of outpatient visits showed mixed results. A study reported that too many outpatient visits would increase the medical expenses and some of the visits are not necessary which will be inefficient in treatment ${ }^{17}$. However, this result was shown when the patients visited multiple doctors for the same condition. Another study reported a shorter return visit interval to be positively associated with blood pressure control 18 .

Non-face-to-face medical telephone counseling/ prescription (telemedicine is the term used in this study) has temporarily approved by Korean government due to a sudden increased number of COVID-19 diagnoses nation-wide. This increase was happened right after a mass infection occurred by an infected person visited a church in Daegu-Gyeongbuk region. The telemedicine center started to operate on March 9, 2020 in Daegu and April 21, 2020 in Seoul. There are some studies reported the positive role of telemedicine and the need of it during infectious disease pandemic era ${ }^{19,20}$, especially in terms of its effectiveness ${ }^{11,21-23}$. From this study, with the telemedicine case, the pattern of healthcare services use has not changed, and it also prevented utilization to be decreased significantly. Considering the fact that hypertension patient's COC had not reduced even though the utilization had decreased, this enlightens the fact that the telemedicine case is effective measure during COVID-19 pandemic period.

Several limitations of this study should be noted. First, this study used hospital administrative data for medical reimbursement or billing, which precludes clinical information meaning that it is hard to confirm whether the patient's actual blood pressure change. Thus, in the future, it is necessary to develop a patient dataset that links administrative data and clinical data on clinical variables such as lab results. Secondly, since only outpatient medical use was targeted, it may have been analyzed that if a patient was hospitalized during the follow-up period due to cardiovascular disease, a complication of hypertension, it was analyzed that he did not use medical care at all. However, in the case of high blood pressure patients with such high severity, it is very important to prevent complications through continuous medical use, so it is considered important to be included in the analysis. Therefore, future studies on hospitalization due to hypertension complications are needed. Lastly, demographic, social structural and economic factors influence medical use. However, in this study, only basic demographic variables such as gender and age, and clinical characteristic variables were included in the analysis because administrative data, which is the data for health insurance review request, was used. As a result, there is a limitation in that the patient's knowledge and attitude toward hypertension are not considered at all. Also, among demographic variables, variables closely related to access to medical institutions, such as residence and income, were not included. To minimize this limitation, in this study, proxy of social economic status and their income level was used as their health insurance status, and a proxy for the participant's condition, CCI was used and controlled. Although, in the future, it is necessary to develop a patient dataset that links administrative data and survey data on social and psychological variables.

Despite its limitations, our study has several strengths. First, the study used nationally representative data. Second, to our knowledge, this study was the first to examine the impact of COVID-19 protocols on hypertension patients' COC in South Korea. Lastly, considering whether the participants were treated by using telemedicine enrichen with the interpretation.

\section{Conclusions}

Our results suggest that COVID-19 protocols did not effect on hypertension patient's COC but had impact on their outpatient frequency. Additionally, when telemedicine cases are considered, COC was the same, but the patient's outpatient frequency had decreased, but not as much as when telemedicine cases were considered. Future studies should consider the inpatient cases whether COVID-19 protocols impacted on hypertensive patient's complication admissions. It is hoped that this information will be a useful reference for further studies of chronic disease patient's COC during pandemic of infections and telemedicine's impact.

\section{Declarations}

\section{Conflicts of Interest}

The authors declare no competing interests.

\section{Author Contributions}

SL has made substantial contributions to the conception, design of the work, interpretation of data, and have drafted the introduction and discussion section of the work or substantively revised it. SC has made substantial contributions to the design of the work and analysis of data. Lastly, HP has made substantial contributions to the design of the work, the acquisition, analysis, interpretation of data, and has drafted the method and result section of the work and revised it. All authors have approved the submitted version and have agreed to be personally accountable for the author's own contributions and to ensure that questions related to the accuracy or integrity of any part of the work, even ones in which the author was not personally involved, are appropriately investigated, resolved, and the resolution documented in the literature.

\section{Acknowledgments}


The authors gratefully acknowledge the assistance of academic specialist Bahar Baniasad MA of University of Illinois at Chicago Academic Center for Excellence with the check and edit of the English in this article.

\section{References}

1 National Health Insurance Service. (National Health Insurance Service, Wonju, 2020).

2 Choi, D. et al. Impact of continuity of care on cardiovascular disease risk among newly-diagnosed hypertension patients. Scientific Reports 10, 19991, doi:10.1038/s41598-020-77131-w (2020).

$3 \mathrm{Kim}, \mathrm{H}$. C. et al. Korea hypertension fact sheet 2020: analysis of nationwide population-based data. Clinical Hypertension 27, 8, doi:10.1186/s40885-021-00166-2 (2021).

4 Shortell, S. M. Continuity of medical care: conceptualization and measurement. Medical care, 377-391 (1976).

5 Bazemore, A. et al. Higher primary care physician continuity is associated with lower costs and hospitalizations. The Annals of Family Medicine 16, 492-497 (2018).

6 Nam, Y. S., Cho, K. H., Kang, H.-C., Lee, K.-S. \& Park, E.-C. Greater continuity of care reduces hospital admissions in patients with hypertension: an analysis of nationwide health insurance data in Korea, 2011-2013. Health Policy 120, 604-611 (2016).

7 Fisher, M., Sloane, P., Edwards, L. \& Gamble, G. Continuity of care and hypertension control in a university-based practice. Ethnicity and Disease 17,693 (2007).

8 Christakis, D. A., Mell, L., Koepsell, T. D., Zimmerman, F. J. \& Connell, F. A. Association of lower continuity of care with greater risk of emergency department use and hospitalization in children. Pediatrics 107, 524-529 (2001).

9 Cayenne, N. A. et al. Association between social isolation and outpatient follow-up in older adults following emergency department discharge. Archives of Gerontology and Geriatrics 93, 104298, doi:https://doi.org/10.1016/j.archger.2020.104298 (2021).

10 Weiskittle, R., Mlinac, M. E. \& Downing, N. Addressing COVID-19 Worry and Social Isolation in Home-Based Primary Care. (2020).

11 Gras, G. Use of telemedicine in the management of infectious diseases. Medecine et maladies infectieuses 48, 231-237 (2018).

12 Kim, J. H., Park, E. C., Kim, T. H. \& Lee, Y. Hospital Charges and Continuity of Care for Outpatients with Hypertension in South Korea: A Nationwide Population-Based Cohort Study from 2002 to 2013. Korean J Fam Med 38, 242-248, doi:10.4082/kjfm.2017.38.5.242 (2017).

13 Van Walraven, C., Oake, N., Jennings, A. \& Forster, A. J. The association between continuity of care and outcomes: a systematic and critical review. Journal of evaluation in clinical practice 16, 947-956 (2010).

14 Christakis, D. A., Mell, L., Wright, J. A., Davis, R. \& Connell, F. A. The association between greater continuity of care and timely measles-mumpsrubella vaccination. American journal of public health 90, 962 (2000).

15 OECD. Health at a Glance 2011. (2011).

16 World Health Organization. Number of outpatient visits per person per year, <https://www.who.int/data/gho/indicator-metadata-registry/imrdetails/3117> (2021).

17 Raddish, M., Horn, S. D. \& Sharkey, P. D. Continuity of care: is it cost effective. Am J Manag Care 5, 727-734 (1999).

18 Guthmann, R., Davis, N., Brown, M. \& Elizondo, J. Visit frequency and hypertension. J Clin Hypertens (Greenwich) 7, 327-332, doi:10.1111/j.15246175.2005.04371.x (2005).

19 Kim, D. et al. Telemedicine Center of Korean Medicine for treating patients with COVID-19: a retrospective analysis. Integrative Medicine Research 9, 100492, doi:https://doi.org/10.1016/j.imr.2020.100492 (2020).

$20 \mathrm{Kim}, \mathrm{H}$. S. Lessons from temporary telemedicine initiated owing to outbreak of COVID-19. Healthcare informatics research 26, 159-161 (2020).

21 Coombes, C. E. \& Gregory, M. E. The current and future use of telemedicine in infectious diseases practice. Current infectious disease reports 21, $1-10$ (2019).

22 Eron, L., King, P., Marineau, M. \& Yonehara, C. Treating acute infections by telemedicine in the home. Clinical infectious diseases $\mathbf{3 9}$, 1175-1181 (2004). 
23 Parmar, P., Mackie, D., Varghese, S. \& Cooper, C. Use of telemedicine technologies in the management of infectious diseases: a review. Clinical Infectious Diseases 60, 1084-1094 (2015).

\section{Tables}


Table 1. General characteristics of population

(cases, \%)

Total

Period

$\mathrm{p}$-value

Before(2019)

After(2020)

\section{Gender}

\begin{tabular}{lrllllll} 
Man & $5,653,558$ & $(48.81)$ & 2826779 & $(48.81)$ & 2826779 & $(48.81)$ & 1.0000 \\
\hline Woman & $5,930,066$ & $(51.19)$ & 2965033 & $(51.19)$ & 2965033 & $(51.19)$ & \\
\hline Age group & & & & & & & \\
\hline 75 and more & $2,674,728$ & $(23.09)$ & 1280358 & $(22.11)$ & 1394370 & $(24.07)$ & $<.0001$ \\
\hline 60 to 74 & $4,974,598$ & $(42.95)$ & 2446950 & $(42.25)$ & 2527648 & $(43.64)$ \\
\hline 45 to 59 & $3,403,191$ & $(29.38)$ & 1775890 & $(30.66)$ & 1627301 & $(28.10)$ \\
\hline 0 to 44 & 508,882 & $(4.39)$ & 276419 & $(4.77)$ & 232463 & $(4.01)$ \\
\hline 0 to 29 & 22,225 & $(0.19)$ & 12195 & $(0.21)$ & 10030 & $(0.17)$
\end{tabular}

Diabetes Mellitus

\begin{tabular}{|c|c|c|c|c|c|c|c|}
\hline Yes & $2,890,161$ & $(24.95)$ & 1394230 & $(24.07)$ & 1495931 & $(25.83)$ & $<.0001$ \\
\hline No & $8,693,463$ & $(75.05)$ & 4397582 & (75.93) & 4295881 & $(74.17)$ & \\
\hline \multicolumn{8}{|l|}{ Hypertension } \\
\hline less than 2 years & 678,704 & $(5.86)$ & 471291 & $(8.14)$ & 207413 & (3.58) & $<.0001$ \\
\hline 2 to 4 years & $2,102,954$ & (18.15) & 1020221 & $(17.61)$ & 1082733 & (18.69) & \\
\hline 5 to 9 years & $2,576,125$ & $(22.24)$ & 1322179 & $(22.83)$ & 1253946 & $(21.65)$ & \\
\hline 10 years and more & $6,225,841$ & $(53.75)$ & 2978121 & $(51.42)$ & 3247720 & $(56.07)$ & \\
\hline $\mathrm{CCl}$ & 0.6402 & \pm 0.9352 & 0.6347 & \pm 0.9227 & 0.6456 & \pm 0.9474 & $<.0001$ \\
\hline \multicolumn{8}{|l|}{ Insurance type } \\
\hline Medical aid & 530,857 & $(4.58)$ & 265298 & $(4.58)$ & 265559 & $(4.59)$ & 0.7138 \\
\hline $\mathrm{NHI}$ & $11,052,767$ & $(95.42)$ & 5526514 & $(95.42)$ & 5526253 & $(95.41)$ & \\
\hline \multicolumn{8}{|l|}{ Region (province) } \\
\hline Sejong-si & 47,252 & $(0.41)$ & 23625 & $(0.41)$ & 23627 & $(0.41)$ & 1.0000 \\
\hline Jeju-si & 143,228 & $(1.24)$ & 71614 & $(1.24)$ & 71614 & $(1.24)$ & \\
\hline Gyeongsangnam-do & 741,163 & $(6.40)$ & 370577 & $(6.40)$ & 370586 & $(6.40)$ & \\
\hline Gyeongsangbuk-do & 699,928 & $(6.04)$ & 349961 & $(6.04)$ & 349967 & $(6.04)$ & \\
\hline Jeollanam-do & 524,119 & $(4.52)$ & 262059 & $(4.52)$ & 262060 & $(4.52)$ & \\
\hline Jeollabuk-do & 499,754 & $(4.31)$ & 249875 & $(4.31)$ & 249879 & $(4.31)$ & \\
\hline Chungcheongnam-do & 522,166 & $(4.51)$ & 261081 & $(4.51)$ & 261085 & $(4.51)$ & \\
\hline Chungcheongbuk-do & 405,470 & $(3.50)$ & 202734 & $(3.50)$ & 202736 & $(3.50)$ & \\
\hline Gangwon-do & 444,728 & $(3.84)$ & 222363 & $(3.84)$ & 222365 & $(3.84)$ & \\
\hline Gyeonggi-do & $2,732,476$ & $(23.59)$ & 1366235 & $(23.59)$ & 1366241 & $(23.59)$ & \\
\hline Ulsan-si & 226,247 & $(1.95)$ & 113124 & $(1.95)$ & 113123 & $(1.95)$ & \\
\hline Daejeon-si & 313,209 & $(2.70)$ & 156606 & $(2.70)$ & 156603 & $(2.70)$ & \\
\hline Gwangju-si & 279,906 & $(2.42)$ & 139953 & $(2.42)$ & 139953 & $(2.42)$ & \\
\hline Daegu-si & 549,508 & $(4.74)$ & 274755 & $(4.74)$ & 274753 & $(4.74)$ & \\
\hline Incheon-si & 668,122 & $(5.77)$ & 334060 & $(5.77)$ & 334062 & (5.77) & \\
\hline Busan-si & 814,482 & (7.03) & 407245 & (7.03) & 407237 & (7.03) & \\
\hline Seoul-si & $1,971,866$ & (17.02) & 985945 & $(17.02)$ & 985921 & $(17.02)$ & \\
\hline
\end{tabular}




\begin{tabular}{lrllllll} 
Institution type & \multicolumn{1}{l}{$\begin{array}{l}\text { (2.74) } \\
\text { Tertiary hospitals }\end{array}$} & 317,701 & $(2.74)$ & 158515 & 159186 & $(2.75)$ & $<.0001$ \\
\hline General hospitals & 999,470 & $(8.63)$ & 498776 & $(8.61)$ & 500694 & $(8.64)$ \\
\hline Hospitals & 644,628 & $(5.56)$ & 324860 & $(5.61)$ & 319768 & $(5.52)$ \\
\hline Public health centers & 406,775 & $(3.51)$ & 272113 & $(4.70)$ & 134662 & $(2.33)$ \\
\hline Clinics & $9,215,050$ & $(79.55)$ & 4537548 & $(78.34)$ & 4677502 & $(80.76)$ \\
\hline Total & $11,583,624$ & $(100.00)$ & 5791812 & $(100.00)$ & 5791812 & $(100.00)$
\end{tabular}


Table 2. MFPC of general population

Total
Period

Before(2019)
(Means $\pm S D$ )

$\mathrm{p}$-value

After(2020)

\section{Gender}

\begin{tabular}{llllllll} 
Man & 0.9502 & \pm 0.1221 & 0.9515 & \pm 0.1207 & 0.9488 & \pm 0.1235 & $<.0001$ \\
\hline Woman & 0.9488 & \pm 0.1218 & 0.9499 & \pm 0.1204 & 0.9477 & \pm 0.1231 & $<.0001$ \\
\hline Age group & & & & & & & \\
\hline 75 and more & 0.9427 & \pm 0.1274 & 0.9457 & \pm 0.1241 & 0.9400 & \pm 0.1303 & $<.0001$ \\
\hline 60 to 74 & 0.9516 & \pm 0.1189 & 0.9533 & \pm 0.1167 & 0.9500 & \pm 0.1208 & $<.0001$ \\
\hline 45 to 59 & 0.9530 & \pm 0.1196 & 0.9526 & \pm 0.1200 & 0.9535 & \pm 0.1191 & $<.0001$ \\
\hline 30 to 44 & 0.9409 & \pm 0.1344 & 0.9387 & \pm 0.1364 & 0.9435 & \pm 0.1320 & $<.0001$ \\
\hline 0 to 29 & 0.9313 & \pm 0.1454 & 0.9284 & \pm 0.1477 & 0.9350 & \pm 0.1424 & 0.0007 \\
\hline
\end{tabular}

Diabetes Mellitus

\begin{tabular}{llllllll} 
Yes & 0.9538 & \pm 0.1161 & 0.9553 & \pm 0.1142 & 0.9524 & \pm 0.1178 & $<.0001$ \\
\hline No & 0.9480 & \pm 0.1238 & 0.9492 & \pm 0.1224 & 0.9468 & \pm 0.1252 & $<.0001$
\end{tabular}

Hypertension

\begin{tabular}{llllllll} 
less than 2 years & 0.9402 & \pm 0.1327 & 0.9373 & \pm 0.1354 & 0.9467 & \pm 0.1262 & $<.0001$ \\
\hline 2 to 4 years & 0.9514 & \pm 0.1210 & 0.9517 & \pm 0.1205 & 0.9510 & \pm 0.1215 & $<.0001$ \\
\hline 5 to 9 years & 0.9511 & \pm 0.1206 & 0.9523 & \pm 0.1193 & 0.9499 & \pm 0.1221 & $<.0001$ \\
\hline 10 years and more & 0.9492 & \pm 0.1215 & 0.9517 & \pm 0.1184 & 0.9468 & \pm 0.1242 & $<.0001$ \\
\hline Insurance type & & & & & & & \\
\hline Medical aid & 0.9479 & \pm 0.1215 & 0.9486 & \pm 0.1207 & 0.9472 & \pm 0.1224 & $<.0001$ \\
\hline NHI & 0.9496 & \pm 0.1220 & 0.9508 & \pm 0.1205 & 0.9483 & \pm 0.1234 & $<.0001$
\end{tabular}

Region (province)

\begin{tabular}{llllllll}
\hline Sejong-si & 0.9426 & \pm 0.1301 & 0.9434 & \pm 0.1294 & 0.9418 & \pm 0.1308 & 0.1912 \\
\hline Jeju-si & 0.9530 & \pm 0.1174 & 0.9511 & \pm 0.1203 & 0.9550 & \pm 0.1144 & $<.0001$ \\
\hline Gyeongsangnam-do & 0.9531 & \pm 0.1173 & 0.9519 & \pm 0.1186 & 0.9543 & \pm 0.1159 & $<.0001$ \\
\hline Gyeongsangbuk-do & 0.9505 & \pm 0.1198 & 0.9529 & \pm 0.1171 & 0.9482 & \pm 0.1225 & $<.0001$ \\
\hline Jeollanam-do & 0.9449 & \pm 0.1246 & 0.9475 & \pm 0.1212 & 0.9423 & \pm 0.1279 & $<.0001$ \\
\hline Jeollabuk-do & 0.9522 & \pm 0.1177 & 0.9506 & \pm 0.1198 & 0.9537 & \pm 0.1156 & $<.0001$ \\
\hline Chungcheongnam-do & 0.9459 & \pm 0.1248 & 0.9461 & \pm 0.1248 & 0.9457 & \pm 0.1248 & 0.2047 \\
\hline Chungcheongbuk-do & 0.9484 & \pm 0.1226 & 0.9517 & \pm 0.1186 & 0.9451 & \pm 0.1263 & $<.0001$ \\
\hline Gangwon-do & 0.9475 & \pm 0.1232 & 0.9521 & \pm 0.1174 & 0.9430 & \pm 0.1286 & $<.0001$ \\
\hline Gyeonggi-do & 0.9475 & \pm 0.1251 & 0.9488 & \pm 0.1236 & 0.9462 & \pm 0.1267 & $<.0001$ \\
\hline Ulsan-si & 0.9559 & \pm 0.1148 & 0.9597 & \pm 0.1091 & 0.9521 & \pm 0.1201 & $<.0001$ \\
\hline Daejeon-si & 0.9522 & \pm 0.1183 & 0.9526 & \pm 0.1180 & 0.9518 & \pm 0.1186 & 0.0690 \\
\hline Gwangju-si & 0.9476 & \pm 0.1238 & 0.9497 & \pm 0.1214 & 0.9456 & \pm 0.1260 & $<.0001$ \\
\hline Daegu-si & 0.9560 & \pm 0.1134 & 0.9553 & \pm 0.1149 & 0.9567 & \pm 0.1119 & $<.0001$ \\
\hline Incheon-si & 0.9521 & \pm 0.1190 & 0.9522 & \pm 0.1191 & 0.9519 & \pm 0.1189 & 0.1824 \\
\hline Busan-si & 0.9531 & \pm 0.1182 & 0.9559 & \pm 0.1146 & 0.9504 & \pm 0.1216 & $<.0001$ \\
\hline Seoul-si & 0.9474 & \pm 0.1248 & 0.9485 & \pm 0.1235 & 0.9462 & \pm 0.1261 & $<.0001$ \\
\hline Institton to & & & & & \\
\hline
\end{tabular}




\begin{tabular}{llllllll} 
Tertiary hospitals & 0.9287 & \pm 0.1532 & 0.9271 & \pm 0.1545 & 0.9304 & \pm 0.1520 & $<.0001$ \\
\hline General hospitals & 0.9457 & \pm 0.1328 & 0.9453 & \pm 0.1329 & 0.9462 & \pm 0.1328 & 0.0004 \\
\hline Hospitals & 0.9365 & \pm 0.1398 & 0.9342 & \pm 0.1419 & 0.9388 & \pm 0.1375 & $<.0001$ \\
\hline Public health centers & 0.9269 & \pm 0.1392 & 0.9436 & \pm 0.1249 & 0.8930 & \pm 0.1592 & $<.0001$ \\
\hline Clinics & 0.9525 & \pm 0.1170 & 0.9537 & \pm 0.1155 & 0.9513 & \pm 0.1184 & $<.0001$ \\
\hline Total & 0.9495 & \pm 0.1219 & 0.9507 & \pm 0.1205 & 0.9483 & \pm 0.1233 & $<.0001$
\end{tabular}


Table 3. Number of outpatient clinic visit per patient

(Means $\pm S D$ )

$\begin{array}{lll}\text { Total } & \text { Period } & \text { p-value } \\ & \text { Before(2019) After(2020) }\end{array}$

\begin{tabular}{|c|c|c|c|c|c|c|c|}
\hline Gender & & & & & & & \\
\hline Man & 7.9359 & \pm 4.9085 & 8.0210 & \pm 4.8419 & 7.8509 & \pm 4.9727 & $<.0001$ \\
\hline Woman & 8.5211 & \pm 5.3288 & 8.6337 & \pm 5.3613 & 8.4084 & \pm 5.2937 & $<.0001$ \\
\hline \multicolumn{8}{|l|}{ Age group } \\
\hline 75 and more & 9.1481 & \pm 6.4048 & 9.3258 & \pm 6.4997 & 8.9850 & \pm 6.3121 & $<.0001$ \\
\hline 60 to 74 & 8.2590 & \pm 4.9318 & 8.3717 & \pm 4.9426 & 8.1498 & \pm 4.9188 & $<.0001$ \\
\hline 45 to 59 & 7.6344 & \pm 4.2311 & 7.7310 & \pm 4.1811 & 7.5289 & \pm 4.2825 & $<.0001$ \\
\hline 30 to 44 & 7.2854 & \pm 4.3218 & 7.3500 & \pm 4.1215 & 7.2085 & \pm 4.5474 & $<.0001$ \\
\hline 0 to 29 & 6.9444 & \pm 4.6984 & 7.0664 & \pm 4.4038 & 6.7961 & \pm 5.0297 & $<.0001$ \\
\hline \multicolumn{8}{|l|}{ Diabetes Mellitus } \\
\hline Yes & 8.8972 & \pm 5.3672 & 9.0337 & \pm 5.3461 & 8.7701 & \pm 5.3836 & $<.0001$ \\
\hline No & 8.0155 & \pm 5.0380 & 8.1130 & \pm 5.0307 & 7.9156 & \pm 5.0434 & $<.0001$ \\
\hline \multicolumn{8}{|l|}{ Hypertension } \\
\hline less than 2 years & 7.7525 & \pm 4.1013 & 7.6707 & \pm 4.1057 & 7.9384 & \pm 4.0852 & $<.0001$ \\
\hline 2 to 4 years & 7.7778 & \pm 4.3948 & 7.9137 & \pm 4.4198 & 7.6497 & \pm 4.3673 & $<.0001$ \\
\hline 5 to 9 years & 8.0065 & \pm 4.8322 & 8.1278 & \pm 4.8228 & 7.8786 & \pm 4.8387 & $<.0001$ \\
\hline 10 years and more & 8.5375 & \pm 5.5548 & 8.6758 & \pm 5.5768 & 8.4107 & \pm 5.5316 & $<.0001$ \\
\hline \multicolumn{8}{|l|}{ Insurance type } \\
\hline Medical aid & 10.2440 & \pm 7.1895 & 10.3710 & \pm 7.2322 & 10.1173 & \pm 7.1443 & $<.0001$ \\
\hline $\mathrm{NHI}$ & 8.1390 & \pm 4.9963 & 8.2369 & \pm 4.9791 & 8.0411 & \pm 5.0115 & $<.0001$ \\
\hline
\end{tabular}

Region (province)

\begin{tabular}{llllllll}
\hline Sejong-si & 8.3671 & \pm 4.7620 & 8.5040 & \pm 4.8872 & 8.2302 & \pm 4.6295 & $<.0001$ \\
\hline Jeju-si & 8.0476 & \pm 4.5007 & 8.1087 & \pm 4.4124 & 7.9865 & \pm 4.5866 & $<.0001$ \\
\hline Gyeongsangnam-do & 8.3869 & \pm 4.9862 & 8.4923 & \pm 4.9973 & 8.2815 & \pm 4.9729 & $<.0001$ \\
\hline Gyeongsangbuk-do & 8.7201 & \pm 4.9404 & 8.8362 & \pm 4.9922 & 8.6040 & \pm 4.8854 & $<.0001$ \\
\hline Jeollanam-do & 9.2460 & \pm 7.0298 & 9.3577 & \pm 7.0874 & 9.1343 & \pm 6.9699 & $<.0001$ \\
\hline Jeollabuk-do & 9.3156 & \pm 6.6059 & 9.3957 & \pm 6.5387 & 9.2355 & \pm 6.6716 & $<.0001$ \\
\hline Chungcheongnam-do & 8.6725 & \pm 5.7471 & 8.7796 & \pm 5.6281 & 8.5654 & \pm 5.8617 & $<.0001$ \\
\hline Chungcheongbuk-do & 8.5476 & \pm 5.0932 & 8.6793 & \pm 5.0696 & 8.4158 & \pm 5.1133 & $<.0001$ \\
\hline Gangwon-do & 7.9901 & \pm 4.3045 & 8.1072 & \pm 4.2810 & 7.8730 & \pm 4.3248 & $<.0001$ \\
\hline Gyeonggi-do & 7.7192 & \pm 4.5631 & 7.8172 & \pm 4.5204 & 7.6211 & \pm 4.6033 & $<.0001$ \\
\hline Ulsan-si & 7.8877 & \pm 4.3847 & 7.9901 & \pm 4.4511 & 7.7854 & \pm 4.3148 & $<.0001$ \\
\hline Daejeon-si & 8.7308 & \pm 4.9401 & 8.8511 & \pm 5.0355 & 8.6105 & \pm 4.8399 & $<.0001$ \\
\hline Gwangju-si & 8.9130 & \pm 5.9559 & 8.9953 & \pm 6.0133 & 8.8308 & \pm 5.8969 & $<.0001$ \\
\hline Daegu-si & 8.8127 & \pm 5.2820 & 8.9259 & \pm 5.2352 & 8.6994 & \pm 5.3259 & $<.0001$ \\
\hline Incheon-si & 8.2082 & \pm 4.7261 & 8.3253 & \pm 4.7811 & 8.0910 & \pm 4.6675 & $<.0001$ \\
\hline Busan-si & 8.1732 & \pm 4.4690 & 8.2547 & \pm 4.4206 & 8.0918 & \pm 4.5155 & $<.0001$ \\
\hline Seoul-si & 7.8048 & \pm 5.2366 & 7.8836 & \pm 5.2198 & 7.7259 & \pm 5.2521 & $<.0001$ \\
\hline Institution type & & & & & & & \\
\hline
\end{tabular}




\begin{tabular}{llllllll} 
Tertiary hospitals & 4.9222 & \pm 3.2682 & 5.0216 & \pm 3.1665 & 4.8233 & \pm 3.3635 & $<.0001$ \\
\hline General hospitals & 5.6255 & \pm 3.3779 & 5.7621 & \pm 3.2843 & 5.4895 & \pm 3.4632 & $<.0001$ \\
\hline Hospitals & 7.0832 & \pm 4.5357 & 7.1699 & \pm 4.2724 & 6.9951 & \pm 4.7869 & $<.0001$ \\
\hline Public health centers & 5.9143 & \pm 3.0225 & 6.0694 & \pm 3.2127 & 5.6009 & \pm 2.5673 & $<.0001$ \\
\hline Clinics & 8.8159 & \pm 5.2848 & 8.9524 & \pm 5.3055 & 8.6834 & \pm 5.2613 & $<.0001$ \\
\hline Total & 8.2355 & \pm 5.1363 & 8.3347 & \pm 5.1236 & 8.1363 & \pm 5.1471 & $<.0001$
\end{tabular}


Table 4. Impact of the COVID-19 protocols on MFPC

With telemedicine cases

\begin{tabular}{|c|c|c|c|c|c|c|c|c|c|c|c|c|}
\hline \multirow[b]{2}{*}{ Intercept } & \multirow{2}{*}{$\begin{array}{l}\beta \\
0.939\end{array}$} & \multirow{2}{*}{$\begin{array}{l}\text { S.E. } \\
0.0011\end{array}$} & \multicolumn{2}{|c|}{$\begin{array}{l}95 \% \text { Confidence } \\
\text { Limits }\end{array}$} & \multirow{2}{*}{$\begin{array}{l}\text { Z } \\
858.89\end{array}$} & \multirow{2}{*}{$\begin{array}{l}\mathrm{p}- \\
\text { value } \\
<.0001\end{array}$} & \multirow{2}{*}{$\begin{array}{l}\beta \\
0.9389\end{array}$} & \multirow{2}{*}{$\begin{array}{l}\text { S.E. } \\
0.0011\end{array}$} & \multicolumn{2}{|c|}{$\begin{array}{l}95 \% \text { Confidence } \\
\text { Limits }\end{array}$} & \multirow{2}{*}{$\begin{array}{l}\text { Z } \\
855.71\end{array}$} & \multirow{2}{*}{$\begin{array}{l}\mathrm{p}- \\
\text { value } \\
<.0001\end{array}$} \\
\hline & & & 0.9369 & 0.9412 & & & & & 0.9368 & 0.9411 & & \\
\hline \multicolumn{13}{|l|}{ Period } \\
\hline After(2020) & -0.0031 & 0.0001 & -0.0032 & -0.0030 & -48.3800 & $<.0001$ & -0.0031 & 0.0001 & -0.0032 & -0.0029 & -47.90 & $<.0001$ \\
\hline Before(2019) & Ref. & - & - & - & - & - & Ref. & - & - & - & - & - \\
\hline \multicolumn{13}{|l|}{ Gender } \\
\hline Man & 0.0003 & 0.0001 & 0.0001 & 0.0005 & 3.7600 & 0.0002 & 0.0003 & 0.0001 & 0.0002 & 0.0005 & 3.92 & $<.0001$ \\
\hline Woman & Ref. & - & - & - & - & - & Ref. & - & - & - & - & - \\
\hline \multicolumn{13}{|l|}{ Age group } \\
\hline 75 and more & 0.0071 & 0.0011 & 0.0049 & 0.0092 & 6.4800 & $<.0001$ & 0.0072 & 0.0011 & 0.0050 & 0.0093 & 6.55 & $<.0001$ \\
\hline 60 to 74 & 0.0148 & 0.0011 & 0.0127 & 0.0170 & 13.6500 & $<.0001$ & 0.0149 & 0.0011 & 0.0128 & 0.0171 & 13.70 & $<.0001$ \\
\hline 45 to 59 & 0.0160 & 0.0011 & 0.0138 & 0.0181 & 14.6900 & $<.0001$ & 0.0160 & 0.0011 & 0.0139 & 0.0182 & 14.70 & $<.0001$ \\
\hline 30 to 44 & 0.0052 & 0.0011 & 0.0031 & 0.0074 & 4.7400 & $<.0001$ & 0.0052 & 0.0011 & 0.0031 & 0.0074 & 4.75 & $<.0001$ \\
\hline 0 to 29 & Ref. & - & - & - & - & - & Ref. & - & - & - & - & - \\
\hline
\end{tabular}

Diabetes Mellitus

$\begin{array}{llllllllllllllll}\text { Yes } & 0.0067 & 0.0001 & 0.0066 & 0.0069 & 77.6800 & <.0001 & 0.0067 & 0.0001 & 0.0066 & 0.0069 & 77.74 & <.0001 \\ \text { No } & \text { Ref. } & - & - & - & - & - & \text { Ref. } & - & - & - & - & - & - & - & -\end{array}$

\section{Hypertension}

2 years

2 to 4 years

5 to 9 years

10 years and more

$\mathrm{CCl}$

Insurance type

Medical aid

$\mathrm{NHI}$

Ref.

$\begin{array}{llll}-0.0102 & 0.0002 & -0.0105 & -0.0098\end{array}$

$\begin{array}{llll}0.0007 & 0.0001 & 0.0005 & 0.0009\end{array}$

$\begin{array}{llll}0.0005 & 0.0001 & 0.0003 & 0.0007\end{array}$

Ref.

$-0.0039$

\begin{tabular}{llllllll}
-56.6300 & $<.0001$ & -0.0101 & 0.0002 & -0.0105 & -0.0098 & -56.41 & $<.0001$ \\
6.4400 & $<.0001$ & 0.0007 & 0.0001 & 0.0005 & 0.0009 & 6.51 & $<.0001$ \\
\hline 5.0500 & $<.0001$ & 0.0005 & 0.0001 & 0.0003 & 0.0007 & 4.96 & $<.0001$ \\
- & - & Ref. & - & - & - & - & - \\
\hline-89.3700 & $<.0001$ & -0.0039 & 0.0000 & -0.0040 & -0.0039 & -89.16 & $<.0001$
\end{tabular}

$0.0000 \quad-0.0040 \quad-0.003$

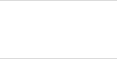

\section{Region (province)}

\begin{tabular}{|c|c|c|c|c|c|c|c|c|c|c|c|c|}
\hline Sejong-si & -0.0057 & 0.0007 & -0.0070 & -0.0044 & -8.5100 & $<.0001$ & -0.0057 & 0.0007 & -0.0070 & -0.0044 & -8.55 & $<.0001$ \\
\hline Jeju-si & 0.0060 & 0.0004 & 0.0053 & 0.0067 & 16.8200 & $<.0001$ & 0.0060 & 0.0004 & 0.0053 & 0.0067 & 16.84 & $<.0001$ \\
\hline $\begin{array}{l}\text { Gyeongsangnam- } \\
\text { do }\end{array}$ & 0.0075 & 0.0002 & 0.0072 & 0.0079 & 42.4500 & $<.0001$ & 0.0076 & 0.0002 & 0.0072 & 0.0079 & 42.61 & $<.0001$ \\
\hline $\begin{array}{l}\text { Gyeongsangbuk- } \\
\text { do }\end{array}$ & 0.0042 & 0.0002 & 0.0039 & 0.0046 & 22.9800 & $<.0001$ & 0.0044 & 0.0002 & 0.0041 & 0.0048 & 24.08 & $<.0001$ \\
\hline Jeollanam-do & -0.0002 & 0.0002 & -0.0006 & 0.0002 & -1.0000 & 0.3166 & -0.0002 & 0.0002 & -0.0006 & 0.0002 & -0.86 & 0.3906 \\
\hline Jeollabuk-do & 0.0063 & 0.0002 & 0.0059 & 0.0067 & 30.5300 & $<.0001$ & 0.0063 & 0.0002 & 0.0059 & 0.0068 & 30.53 & $<.0001$ \\
\hline $\begin{array}{l}\text { Chungcheongnam- } \\
\text { do }\end{array}$ & -0.0009 & 0.0002 & -0.0013 & -0.0004 & -4.0100 & $<.0001$ & -0.0009 & 0.0002 & -0.0013 & -0.0004 & -3.99 & $<.0001$ \\
\hline $\begin{array}{l}\text { Chungcheongbuk- } \\
\text { do }\end{array}$ & 0.0011 & 0.0002 & 0.0006 & 0.0015 & 4.7200 & $<.0001$ & 0.0012 & 0.0002 & 0.0007 & 0.0016 & 5.11 & $<.0001$ \\
\hline Gangwon-do & 0.0011 & 0.0002 & 0.0007 & 0.0016 & 5.0600 & $<.0001$ & 0.0012 & 0.0002 & 0.0007 & 0.0016 & 5.23 & $<.0001$ \\
\hline Gyeonggi-do & 0.0001 & 0.0001 & -0.0002 & 0.0003 & 0.4600 & 0.6459 & 0.0001 & 0.0001 & -0.0002 & 0.0003 & 0.43 & 0.6686 \\
\hline Ulsan-si & 0.0084 & 0.0003 & 0.0078 & 0.0089 & 30.1700 & $<.0001$ & 0.0084 & 0.0003 & 0.0078 & 0.0089 & 30.06 & $<.0001$ \\
\hline
\end{tabular}




\begin{tabular}{|c|c|c|c|c|c|c|c|c|c|c|c|c|}
\hline Daejeon-si & 0.0037 & 0.0003 & 0.0033 & 0.0042 & 14.9500 & $<.0001$ & 0.0037 & 0.0003 & 0.0032 & 0.0042 & 14.88 & $<.0001$ \\
\hline Gwangju-si & 0.0017 & 0.0003 & 0.0012 & 0.0022 & 6.1700 & $<.0001$ & 0.0017 & 0.0003 & 0.0012 & 0.0022 & 6.19 & $<.0001$ \\
\hline Daegu-si & 0.0089 & 0.0002 & 0.0086 & 0.0093 & 46.1800 & $<.0001$ & 0.0088 & 0.0002 & 0.0084 & 0.0092 & 45.17 & $<.0001$ \\
\hline Incheon-si & 0.0043 & 0.0002 & 0.0040 & 0.0047 & 23.2700 & $<.0001$ & 0.0043 & 0.0002 & 0.0039 & 0.0047 & 22.90 & $<.0001$ \\
\hline Busan-si & 0.0072 & 0.0002 & 0.0068 & 0.0075 & 41.3900 & $<.0001$ & 0.0074 & 0.0002 & 0.0070 & 0.0077 & 42.39 & $<.0001$ \\
\hline Seoul-si & Ref. & - & - & - & - & - & Ref. & - & - & - & - & - \\
\hline \multicolumn{13}{|l|}{ Institution type } \\
\hline Tertiary hospitals & -0.0227 & 0.0003 & -0.0233 & -0.0221 & -72.3400 & $<.0001$ & -0.0232 & 0.0003 & -0.0238 & -0.0226 & -73.22 & $<.0001$ \\
\hline General hospitals & -0.0065 & 0.0002 & -0.0068 & -0.0062 & -41.2600 & $<.0001$ & -0.0068 & 0.0002 & -0.0071 & -0.0064 & -42.62 & $<.0001$ \\
\hline Hospitals & -0.0167 & 0.0002 & -0.0171 & -0.0163 & -83.3900 & $<.0001$ & -0.0168 & 0.0002 & -0.0172 & -0.0164 & -83.97 & $<.0001$ \\
\hline $\begin{array}{l}\text { Public health } \\
\text { centers }\end{array}$ & -0.0100 & 0.0002 & -0.0105 & -0.0096 & -42.2100 & $<.0001$ & -0.0103 & 0.0002 & -0.0108 & -0.0099 & -43.40 & $<.0001$ \\
\hline Clinics & Ref. & - & - & - & - & - & Ref. & - & - & - & - & - \\
\hline
\end{tabular}


Table 5. Impact of the COVID-19 protocols on the number of outpatient clinic visit per patient

With telemedicine cases

\begin{tabular}{|c|c|c|c|c|c|c|c|c|c|c|c|c|}
\hline \multirow[b]{2}{*}{ Intercept } & \multirow{2}{*}{$\begin{array}{l}\beta \\
8.0054\end{array}$} & \multirow{2}{*}{$\begin{array}{l}\text { S.E. } \\
0.0353\end{array}$} & \multicolumn{2}{|c|}{$\begin{array}{l}95 \% \text { Confidence } \\
\text { Limits }\end{array}$} & \multirow{2}{*}{$\begin{array}{l}Z \\
227.06\end{array}$} & \multirow{2}{*}{$\begin{array}{l}\text { p- } \\
\text { value } \\
<.0001\end{array}$} & \multirow{2}{*}{$\begin{array}{l}\beta \\
8.0105\end{array}$} & \multirow{2}{*}{$\begin{array}{l}\text { S.E. } \\
0.0354\end{array}$} & \multicolumn{2}{|c|}{$\begin{array}{l}95 \% \text { Confidence } \\
\text { Limits }\end{array}$} & \multirow{2}{*}{$\begin{array}{l}Z \\
226.24\end{array}$} & \multirow{2}{*}{$\begin{array}{l}\mathrm{p}- \\
\text { value } \\
<.0001\end{array}$} \\
\hline & & & 7.9363 & 8.0745 & & & & & 7.9411 & 8.0799 & & \\
\hline \multicolumn{13}{|l|}{ Period } \\
\hline After(2020) & -0.2930 & 0.0016 & -0.2962 & -0.2899 & -181.43 & $<.0001$ & -0.3330 & 0.0016 & -0.3362 & -0.3299 & -205.22 & $<.0001$ \\
\hline Before(2019) & Ref. & - & - & - & - & - & Ref. & - & - & - & - & - \\
\hline \multicolumn{13}{|l|}{ Gender } \\
\hline Man & -0.2548 & 0.0039 & -0.2624 & -0.2472 & -65.77 & $<.0001$ & -0.2527 & 0.0039 & -0.2603 & -0.2451 & -65.13 & $<.0001$ \\
\hline Woman & Ref. & - & - & - & - & - & Ref. & - & - & - & - & - \\
\hline \multicolumn{13}{|l|}{ Age group } \\
\hline 75 and more & 0.9864 & 0.0351 & 0.9176 & 1.0552 & 28.10 & $<.0001$ & 0.9921 & 0.0353 & 0.9230 & 1.0612 & 28.14 & $<.0001$ \\
\hline 60 to 74 & 0.3353 & 0.0348 & 0.2671 & 0.4035 & 9.63 & $<.0001$ & 0.3385 & 0.0350 & 0.2700 & 0.4071 & 9.69 & $<.0001$ \\
\hline 45 to 59 & -0.1031 & 0.0347 & -0.1711 & -0.0350 & -2.97 & 0.0030 & -0.1040 & 0.0349 & -0.1724 & -0.0356 & -2.98 & 0.0029 \\
\hline 30 to 44 & -0.2437 & 0.0350 & -0.3124 & -0.1750 & -6.95 & $<.0001$ & -0.2434 & 0.0352 & -0.3124 & -0.1745 & -6.92 & $<.0001$ \\
\hline 0 to 29 & Ref. & - & - & - & - & - & Ref. & - & - & - & - & - \\
\hline \multicolumn{13}{|l|}{ DB } \\
\hline Yes & 0.5026 & 0.0039 & 0.4950 & 0.5103 & 128.97 & $<.0001$ & 0.5012 & 0.0039 & 0.4936 & 0.5089 & 128.37 & $<.0001$ \\
\hline No & Ref. & - & - & - & - & - & Ref. & - & - & - & - & - \\
\hline
\end{tabular}

\section{Hypertension}

2 years

$-0.1023$

0.0058

$-0.1137$

2 to 4 years

$\begin{array}{rrr}-0.1023 & 0.0058 & -0.1137 \\ -0.2898 & 0.0042 & -0.2980\end{array}$

5 to 9 years

$-0.1826$

10 years and more

Ref.

$\mathrm{CCl}$

0.1220

0.003

$-0.1897$

$-0.0909$

$-17.58<.0001$

$-0.1043$

0.0058

$-0.1157$

$-0.0929$

$-17.88$

$<.0001$

$-0.2815-69.11<.0001$

$\begin{array}{lll}-0.2874 & 0.0042 & -0.2956\end{array}$

$-0.279$

$-68.38<.0001$

$-0.1756-50.95<.0001$

$-0.1818$

0.0036

$-0.1888$

$-0.1747$

Ref.

\section{Insurance type}

Medical aid

$\mathrm{NHI}$

$\begin{array}{llllll}1.8853 & 0.0127 & 1.8605 & 1.9101 & 148.96 & <.0001 \\ \text { Ref. } & - & - & - & - & -\end{array}$

Region (province)

\begin{tabular}{|c|c|c|c|c|c|c|c|c|c|c|c|c|}
\hline Sejong-si & 0.4773 & 0.0276 & 0.4233 & 0.5314 & 17.31 & $<.0001$ & 0.4713 & 0.0276 & 0.4173 & 0.5254 & 17.09 & $<.0001$ \\
\hline Jeju-si & 0.3895 & 0.0152 & 0.3597 & 0.4193 & 25.62 & $<.0001$ & 0.3941 & 0.0152 & 0.3643 & 0.4239 & 25.91 & $<.0001$ \\
\hline $\begin{array}{l}\text { Gyeongsangnam- } \\
\text { do }\end{array}$ & 0.8056 & 0.0087 & 0.7886 & 0.8226 & 92.90 & $<.0001$ & 0.8034 & 0.0087 & 0.7864 & 0.8205 & 92.50 & $<.0001$ \\
\hline $\begin{array}{l}\text { Gyeongsangbuk- } \\
\text { do }\end{array}$ & 1.0135 & 0.0087 & 0.9966 & 1.0305 & 117.04 & $<.0001$ & 0.9992 & 0.0087 & 0.9822 & 1.0162 & 115.13 & $<.0001$ \\
\hline Jeollanam-do & 1.4879 & 0.0133 & 1.4619 & 1.5139 & 112.12 & $<.0001$ & 1.4892 & 0.0133 & 1.4631 & 1.5152 & 112.12 & $<.0001$ \\
\hline Jeollabuk-do & 1.4908 & 0.0128 & 1.4658 & 1.5158 & 116.84 & $<.0001$ & 1.4862 & 0.0128 & 1.4612 & 1.5113 & 116.39 & $<.0001$ \\
\hline $\begin{array}{l}\text { Chungcheongnam- } \\
\text { do }\end{array}$ & 0.9117 & 0.0111 & 0.8899 & 0.9335 & 82.10 & $<.0001$ & 0.9063 & 0.0111 & 0.8845 & 0.9281 & 81.55 & $<.0001$ \\
\hline $\begin{array}{l}\text { Chungcheongbuk- } \\
\text { do }\end{array}$ & 0.7342 & 0.0110 & 0.7126 & 0.7558 & 66.60 & $<.0001$ & 0.7355 & 0.0111 & 0.7139 & 0.7572 & 66.49 & $<.0001$ \\
\hline Gangwon-do & 0.3207 & 0.0092 & 0.3026 & 0.3387 & 34.80 & $<.0001$ & 0.3257 & 0.0092 & 0.3077 & 0.3438 & 35.32 & $<.0001$ \\
\hline Gyeonggi-do & 0.0425 & 0.0058 & 0.0310 & 0.0540 & 7.27 & $<.0001$ & 0.0414 & 0.0059 & 0.0299 & 0.0529 & 7.07 & $<.0001$ \\
\hline Ulsan-si & 0.3330 & 0.0124 & 0.3088 & 0.3573 & 26.90 & $<.0001$ & 0.3265 & 0.0124 & 0.3023 & 0.3508 & 26.39 & $<.0001$ \\
\hline
\end{tabular}




\begin{tabular}{lllllllllllll}
\hline Daejeon-si & 0.8033 & 0.0120 & 0.7798 & 0.8267 & 67.18 & $<.0001$ & 0.7987 & 0.0120 & 0.7753 & 0.8222 & 66.77 & $<.0001$ \\
\hline Gwangju-si & 1.2873 & 0.0148 & 1.2583 & 1.3164 & 86.77 & $<.0001$ & 1.2666 & 0.0148 & 1.2375 & 1.2957 & 85.30 & $<.0001$ \\
\hline Daegu-si & 0.9177 & 0.0101 & 0.8978 & 0.9376 & 90.43 & $<.0001$ & 0.8831 & 0.0102 & 0.8632 & 0.9031 & 86.76 & $<.0001$ \\
\hline Incheon-si & 0.4702 & 0.0085 & 0.4535 & 0.4870 & 55.11 & $<.0001$ & 0.4712 & 0.0085 & 0.4545 & 0.4880 & 55.15 & $<.0001$ \\
\hline Busan-si & 0.5357 & 0.0077 & 0.5206 & 0.5508 & 69.61 & $<.0001$ & 0.5343 & 0.0077 & 0.5192 & 0.5494 & 69.32 & $<.0001$ \\
\hline Seoul-si & Ref. & - & - & - & - & - & Ref. & - & - & - \\
\hline Institution type & & & & & & & & - & - \\
\hline Tertiary hospitals & -3.5721 & 0.0114 & -3.5944 & -3.5498 & -314.18 & $<.0001$ & -3.5519 & 0.0114 & -3.5743 & -3.5296 & -311.21 & $<.0001$ \\
\hline General hospitals & -3.0503 & 0.0059 & -3.0619 & -3.0387 & -515.35 & $<.0001$ & -3.0425 & 0.0059 & -3.0541 & -3.0309 & -513.34 & $<.0001$ \\
\hline Hospitals & -1.6180 & 0.0081 & -1.6338 & -1.6021 & -200.52 & $<.0001$ & -1.6121 & 0.0081 & -1.6279 & -1.5963 & -199.96 & $<.0001$ \\
\hline $\begin{array}{l}\text { Public health } \\
\text { centers }\end{array}$ & -2.1993 & 0.0065 & -2.2120 & -2.1866 & -339.53 & $<.0001$ & -2.2147 & 0.0065 & -2.2275 & -2.2020 & -340.67 & $<.0001$ \\
\hline Clinics & & & & - & - & - & - & Ref. & - & - & -
\end{tabular}

